\title{
Purchasing Intentions toward Fast Food: The Mediating Role of Consumer Attitudes toward Fast Food
}

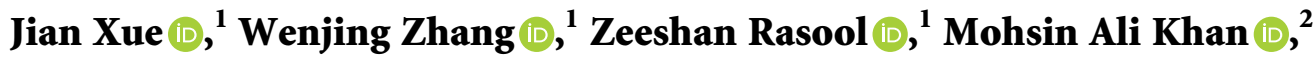 \\ Ahmad Imran Khan $\mathbb{D},{ }^{3}$ Anum Afzal Khan $\mathbb{D}^{3},{ }^{3}$ and Syed Arslan Abbas $\mathbb{D}^{4}$ \\ ${ }^{1}$ School of Economics and Management, Shaanxi University of Science and Technology, Xi'an 710021, China \\ ${ }^{2}$ National University of Modern Languages, Multan Campus, Islamabad, Pakistan \\ ${ }^{3}$ Putra Business School, University of Putra (UPM), Serdang 43400, Selangor, Malaysia \\ ${ }^{4}$ Faculty of Business,Law, and Social Sciences, Birmingham City University, 4 Cardigan Street, Birmingham, UK
}

Correspondence should be addressed to Zeeshan Rasool; zeeshan_rasool114@hotmail.com

Received 31 March 2021; Revised 31 May 2021; Accepted 15 July 2021; Published 29 August 2021

Academic Editor: Tatsadjieu Ngouné Léopold

Copyright ( $) 2021$ Jian Xue et al. This is an open access article distributed under the Creative Commons Attribution License, which permits unrestricted use, distribution, and reproduction in any medium, provided the original work is properly cited.

\begin{abstract}
We highlight the role of fast food awareness and the features affecting the intentions of individuals buying it. The fast food industry is developing rapidly, opening new doors for various stakeholders. The objective of the study is to identify the impact of knowledge of fast food on the desire to buy fast food, study its impact on fast food purchasing intentions, and uncover the effect of fast food attitudes on consumers' purchasing intentions and intention patterns. Several studies discuss the factors prompting fast food purchases, but convincing findings have not been reported. The previous research did not disclose some significant variables influencing consumers' fast food-related decisions, namely, knowledge and uniqueness-seeking qualities. The existing studies are centered on connections between facts about fast food and unique consumer traits (independent variables), attitudes toward fast food (mediator), and fast food purchasing expectations (dependent variable). The mediator between attitudes toward fast food and fast food purchasing intentions is family structure. In previous studies, the variables and connections were examined from a different perspective. The study's data were collected through a questionnaire, and 279 consumers frequenting well-known shops in Pakistan were sampled. To provide statistical evidence, exploratory factor analysis, confirmatory factor analysis, and multigroup moderations were performed. Knowledge of fast food and uniqueness-seeking characteristics were relevant both directly and through mediation when predicting fast food purchasing intentions. The hypothesized direction between attitudes toward fast food and fast food purchases was also significantly moderated by family structure. This study is the first of its kind and helps identify the fast food purchasing behaviors of consumers in developing countries. The shift from joint family systems to a nuclear family model is a particularly important change in the social experience of food.
\end{abstract}

\section{Introduction}

1.1. Background of the Study. The fast food industry is growing tremendously, and the fast food segment of the market is providing financial incentives to stakeholders. This has led advertisers to consider the factors behind each person's desire to buy fast food. As has been noted, "the main appeal of fast food for people is taste and hygiene" [1]. Despite its affordability and the growth of the sector, the variables that influence fast food purchasing decisions, particularly in developing countries, are still underexplored.
Various studies and a relatively large body of literature allude to the conditions contributing to fast food purchasing decisions, but consistent, compelling results have not yet been presented. The previous investigations did not identify any significant variables related to knowledge or the search for high quality that affected the fast food-related decisions of customers. As has also been noted, "food knowledge is in every respect strongly linked to the need for nutrition, particularly because of meat and vegetables" [2]. The key challenge for vendors is to grasp the causes of this shifting trend from traditional meal planning to fast food 
consumption. Fast food awareness and the specific characteristics of fast food consumers can impact fast food choices. Noteworthy research has been done on these factors to explore the relationship between these variables and anticipate fast food purchasing trends. In this paper, we explore the theory of value credentials and expected actions to assess the standards of consumer behavior. The research shows the convictions formed by several components (learning, ability, and commonalities) and is central to understanding the production of attitudes [3].

Furthermore, "attitude claims the way an essay is performed" [4]. Within this analysis, the VBS (value belief standard) and TEB (theory of expected behavior) are used to assess its significance when clarifying social goals related to fast food. Furthermore, the theories have been well tested in prior studies to explain the role of behavioral preferences, attitudes, and multiple variables. Expectations represent plans, goals, or expected events. Sellers' main interests depend on an understanding of the goals behind various buying choices. Therefore, individuals' goals regarding various products were usually understood in the past, but fast food goals remain miscalculated, especially in underdeveloped nations such as Pakistan. The aims of various topics, such as foodstuffs, social security, religious movements, and aspirations, have been discussed in previous studies in relation to many specific products and companies. For the majority, a smart diet and high-quality goods are preferable [5]. In studies related to personal aspirations and social norms, regarding social commitments, consumers displayed one-sided perceptions [6]. Generally, people should not attempt to hide their real perceptions of an object for various reasons, such as the fact that an individual can demonstrate a positive identity within society.

In fact, experienced clients occasionally hear from their communities about products that come from various sources, such as retailers' inventories, online databases, or websites. According to the study, the desire to get a good deal is growing because clients have a lot of knowledge or data on various subjects. The authors of the study also pointed to the need to educate repeat consumers because they have less knowledge of new items in various categories, so they may have greater negative expectations for new items [7].

Furthermore, it was noted that as consumers become more experienced, most of them care less about new products and fail to search for them because they do not want to look for new alternatives, so they have poor attitudes toward new items. Knowledge of various products can be used to strengthen a company in this way [8]. Written material is studied for various purposes, such as gaining knowledge of sports and medical facilities, but knowledge of fast food has not been studied the same way. Therefore, the effect of fast food knowledge should be studied so that its influence on customers' buying preferences can be seen. However, previous experience is not useful in the quest for understanding the individual characteristics of customers.

Uniqueness-seeking behaviors are the hallmark of a specific type of person's identity, and they can be distinguished by an excitement to embrace various kinds of risks, such as physical, social, and legal ones, which are financially linked to taking the initiative with new items, or those that are "not the same old thing but fresh, varied, and strong" [9]. Unique search features tend to create interest in creative solutions among customers. Using similar products daily leaves consumers bored. Thus, they look to each other for pleasure, feedback, and unique experiences. Often people experiment with a novel type of food and wish to try it in specific situations [10]. They may also adopt alternative homemade foods to make the everyday routine more varied. The risk associated with trying new products influences the basic path of the consumer. Individuals typically avoid risky situations and attempt to keep a safe distance from physical, financial, or psychological risks. It has been found that consumers maintain a strategic distance from some kinds of food to prevent various kinds of bad luck [11]. This includes a few customers avoiding the search for new items to reduce the possibility of newer issues. Likewise, in the medical sector, people deliberately avoid pursuing new drugs or treatments for a psychiatric or physical condition when they object to taking new prescription medications. People attempt to protect themselves by using proven approaches and medicines [12]. The personality of an individuals is, therefore, distinguished by whether they seek out new experiences. New technologies are being tried in the quest for innovation, but many people keep a strategic distance from them to avoid danger.

Personality characteristics are an integral aspect of analyzing the uniqueness-seeking behaviors of consumers. Previous studies have showed how specific personality traits affect the actions of customers. The frameworks analyzing identity attributes and their impacts on consumer decisions can be seen in the critical research. It was unquestioned for people who are curious to use a margin for building their mood to make an object [13]. Several studies have provided ample information about buyers purchasing various objects, as shown by their intentions regarding fashion items [14]. This paper will aid in identifying the characteristics related to the purchase of fast foods. The paper's value depends on identifying the personality characteristics that influence the purchase of fast food items. It will help to explain the many factors influencing food selection. This exceptional research will help to clarify environment-based causes. The principles of VBN and TPB are used to illustrate the impact of fast food offerings on the consumer's food selection process. The fast food market is growing; thus, we must identify the proper causes of fast food market growth before conducting research on the fast food industry. In other words, the market alters consumers' behaviors regarding fast food products. These findings in this paper will allow marketing departments to efficiently execute successful marketing strategies for fast food products.

1.2. Theory of Planned Behavior. "Attitude" is a combination of somebody's philosophies, feelings, and theories. A person's attitude can be transformed into desirable behaviors if appropriate behavioral tools are available (Ajzen, 1991). As an extension of the theory of reasoned action, the theory of planned behavior (TPB) states that a positive attitude toward 
goods transforms purchasing behaviors (Ajzen, 1991). Behavioral intentions dependent on attitude produce similar behaviors (Schiffman \& Kanuk, 2004). Furthermore, as an explanation of behavior through attitude, the theory of planned behavior explains the space between attitude and behavior by introducing the concept of behavioral controls (Ajzen, 1991). This paper considered family structure an important determinant of attitudes toward fast foods and consumers' purchasing priorities.

Family structure can refer to various types of living arrangements among families. Some households prefer to live as an extended family, while some prefer to live as isolated units. If a household contains a couple of parents and their offspring, it is called a nuclear household. A family involving multiple nuclear households and uncles, aunts, and/or grandparents is called an extended/joint family. The structure has very significant role in the purchase of appropriate meals. The rules of families restrict purchasers' buying decisions. Osborne and McLanahan (2007) examined the fact that the structure of a household plays a moderating rule in purchasing decisions. In particular, with an increase in joint family systems, there are fewer appropriate nutrition choices than in nuclear family systems.

1.3. Research Objectives. The existing studies are centered on connections between facts about fast food and uniquenessseeking traits (independent variables), attitudes toward fast food (mediator), and fast food purchasing expectations (dependent variable). In line with its role in terms of fast food purchases, the role of mediator is taken over by the family system. In previous studies, various variables and their relationships within specific contexts have been discussed. The following priorities are emphasized in the present analysis:

(1) Identify the impact of fast food knowledge on the desire to buy fast food and its impact on fast food purchasing intentions in relation to uniquenessseeking traits.

(2) Identify the effect of fast food knowledge on the intention to purchase it and intention patterns.

(3) Explore the relationship between knowledge of fast food; the mediator's effect on fast food; and the specific characteristics, social effects, and perceptions related to fast food purchases.

(4) Classify the effect of family structure on the relationship between attitudes toward fast food.

The novel contribution of this research is that it presents a proof: no combination of variables in a coordinated system was observed previously; thus, our findings fill a research gap. The effects of the two independent variables on fast food purchasing behaviors have never been contemplated considering the mediating effect of attitudes toward fast food. The fast food sector was chosen as the research topic because of numerous factors. It is a quickly developing sector in advanced and developing nations. Fast food consumers are increasing enormously in Pakistan. According to the literature, knowledge of fast food and uniqueness-seeking qualities are a significant element contributing to the development of the fast food industry. Thus, the findings of this study will be useful for the development of marketing strategies for the fast food industry.

1.4. Problem Statement. There is a predicament among Pakistan's fast food producers. While fast food is widely sold (as in many other countries), sales lag in Pakistan. The growth of many fast food companies has been negatively affected by this issue. Consumers' low level of knowledge of fast food items, various social factors, and consumers' lifestyles are possible explanations for this issue. This research, which is an investigation of the factors behind the purchasing of fast foods via a quantitative analysis, is aimed at reversing the situation.

The fundamental goal of this research is to discover the drivers of the issue and to further the research on the topic. This section begins with the background of the study and it involves a discussion of the importance of awareness and connections between planned variables, i.e., knowledge of fast foods, the modification of search behaviors, assertiveness about the direction of nutrition, and goals related to fast foods. In this paper, information about fast food and the various consumer characteristics that may affect the likelihood of purchasing it are observed. We have also observed how families think about fast food and what their response is toward the purchase of these food items. The abundant literature provides adequate knowledge about purchasers' purchasing intentions toward a variety of manufactured goods. O'Cass and Frost (2002) observed shoppers' intentions regarding fashion items. Likewise, O'Leary (2005) analyzed behaviors related to broadband facilities in cellular manufacturing. Supplementary research by Ottman (1993) has assessed consumption goals for green crops, and Feldman and Lynch (1988) deliberated the aims for vehicle purchases; however, purchasers' intent concerning fast foods is still especially underexplored in emerging countries like Pakistan. The present paper may aid in discovering the consumer characteristics related to the decision to purchase fast foods.

The importance of the paper depends on presenting the practical effects of the information and the variations in the characteristics that affect the purchase of fast food items. This paper may help readers understand the many factors that have a significant effect on the selection of food items. Our plan may help to engender an understanding of the factors from an educational point of view. Additionally, the VBN and TPB concepts clarify the influence of combined causes on consumers' fast food selections. As can be seen, the fast food market is increasing, so before we attempt to perform research in the fast food sector, we must understand the characteristics contributing to the growth of the fast food market. In other words, it can be said that the market can 
cause modifications in the behavior of consumers regarding fast food. This paper will help marketing teams prepare good advertising campaigns to market fast food items effectively.

\section{Literature Review}

2.1. Knowledge about Fast Foods. Since awareness is considered an essential part of life, it is characterized by various fields of study. As renowned logicians, scientists and researchers [15] define awareness as a practical, correct belief. It has been suggested that training depends on persuasion. This means that individuals have subjective views as well as knowledge. According to another source, the study of certainties, rules, or basic beliefs is characteristic of awareness. It is also well known that people are generally supported by their convictions (knowledge); thus, we should consider how to increase the likelihood of people gaining awareness of fast food. When consumers possess more knowledge about items, it makes it easier for consumers to access them. Knowledge can create confidence in consumers when contemplating trying new items, like convenience foods.

As has been noted, "customer awareness and knowledge have a huge influence on their food decisions" [16]. In addition, the following has been said of consumers about the awareness of food when making purchasing choices: “a comment on a certain form of food has a major effect on consumers' intentions" [17]. Through brand awareness, external signals, prices, perceived risks, and financial incentives, consumers' intentions are influenced by knowledge and family structure [18].

In addition, it was found that differences among shoppers in terms of advertisement outcomes exist in real life and reflect a lack of awareness and the presence of fewer targets than for ordinary foods [19]. In this way, item awareness is an essential part of the popularity and quality of a brand. Any instance in which someone speaks or writes involves knowledge of invisible concepts and facts. This is true regardless of the source of the knowledge, and the data sources are mostly figures [20]. Based on all these facts, it has been mentioned that without regard to the assessment source, information has various forms and uses.

The measurement of awareness is not difficult. After analyzing information, one can quickly imagine where knowledge came from and how it was discovered. Books, journals, teachers, and social groups are the most popular sources of information. Literature is another source of information, and it is considered both a good and bad source. It has been said that information can be used for a public reason by someone with a private motive [14].

To put it more precisely, it was never essential to specify where information was derived from, but it was used for specific purposes, such as evaluation, purchases of items, or the making of proposals. It has been recognized that awareness has a positive effect on purchasers' decisionmaking capabilities. Consumers only buy products about which they feel they have enough knowledge. The behaviors of individuals in the field of environmental protection were also evaluated in accordance with their levels of awareness [21].
2.2. Uniqueness-Seeking Traits. Individual features are known as personality qualities by psychologists. As the latest research shows, the quest for uniqueness is related to research exercises that rely on new stimuli [22]. Individuals are empowered to look for new items with unique qualities. Persons with strong specific characteristics seek different things and are usually driven and have unpredictable personalities. Uniqueness-seeking in the quest for higher quality encourages people to find new solutions to old issues to resolve dissatisfaction in combination with old methods. Individuals with solid uniqueness-seeking characteristics seek to extend their degree of fulfillment and they share four assets, as follows: (1) investigative sensitivity; (2) impulsiveness; (3) extravagance; and (4) chaos.

This means that the interest of individuals may be sparked by the quality of uniqueness (personality characteristics). In addition to naturally occurring resources, people may hunt for unexpected things for many reasons [23]. Specific characteristics are characteristics of identity and immediately affect individual social expectations. Often individual examples that are contrary to a person's identity are just interpretations of their identity. Identity evaluation situations illustrate people's attitude toward the Earth and new objects, such as the search for individuality and oddity [24].

A person's specific personality is composed of many characteristics, which are shown not only by a person's methodology/immediate response to new items or hazardous situations but also by their desire to buy remarkable items [25]. The primary findings of both research and interest would be that consumers like to buy new items. Thus, the unique search for identity-related features has a unique effect on the decisions of consumers regarding various items. We want to do new things with the same resources but cannot, and thus we must do new things with new resources. There are two types of people in society: those who rely on others to obtain things and are less confident and others who seek new things on their own [26]. The knowledge in various fields was evaluated in direct connection with various forms of intellectual creativity, flexibility, and originality, if people have more constructive intentions in relation to modern subjects.

2.3. Attitude toward Fast Foods. Attitude has other meanings in this analysis and in the results of many other researchers. Notwithstanding the fact that the pattern of meanings associated with attitude has persisted, the uses of the term in various contexts are distinctive. In 1960, Alexander Bain used "attitude" first and made it clear that he was prepared to look inward. Numerous scientists have subsequently pondered the meaning of the word "attitude" in relation to its connection with behavior. They have characterized the term attitude as an assessment of a negative or positive quality held by an article or person [27].

Throughout this context, various researchers have contrastingly defined the significance of the variable meaning of "attitude" throughout various studies. This is an essential aspect of the discussion, which must be understood 
to summarize it, and it has been studied extensively in various works. The past work addresses a deeply consistent mindset and its effect on the social perceptions of customers. As has been noted, "most significant discoveries view disposition as these, as it is a forerunner to social expectations" [14].

It has been claimed that behavioral motives should take priority, as consumers are mainly influenced by actions, and they behave consistently according to their status. "Our mindset is the driving force behind our business planning," according to Hawkins (1989). "That is why we make our marketing campaign based on our understanding and knowledge of the range. It has been decided that Chinese consumers are not interested in the US restaurant holder because they do not offer services" [28].

2.4. Family Structure. In large measure, the structure of the family involves various types of family members or connections with specific family members. In the context of a collective family unit or in a separate one, the unit typically includes guardians and their children. Thus, a family consisting of two adults and their children is characterized as a family unit or separate family [29].

Where a family includes uncles, aunts, grandparents, and so on, it is an extended family. A family arrangement may also have two main groups that coexist as a blended family and a separate family. Numerous relatives such as grandparents, uncles, aunts, and stepparents may be part of a joint family, whereas only two parents and their own children are included in a nuclear family.

Many researchers describe the structure of a family unit as consisting of just a couple and their children. The two family arrangements still present an extraordinary comparison. In Pakistan, 67\% of families (Gallup Pakistan, 2010) were joint ones, $31 \%$ were nuclear, and the Gallup experts said that $2 \%$ of the families did not respond. Pakistan has similar types of family structures in which very specific family values are prominent.

Family structure affects consumer behaviors. The buying choices of consumers are constrained by family values, local laws, and guidelines. Individuals strive to demonstrate behaviors that are admirable according to their families' values to enjoy a high level of esteem. The structure of a family also affects the goals of its members. Researchers have discussed the odds of people demonstrating negative behaviors in relation to family expectations [30].

The main aim of this research is to discover the role of household structure in the development of behaviors related to fast food purchases. The use of drugs plays a significant role in a family's welfare [31]. In contrast with children who receive adequate parental care, children who are deprived of the attention of their mother and father are less developed. Variations in family structure have been shown to have a bad influence on the disposition of the offspring and their likelihood of making healthy choices [32].

2.5. Fast Food Purchasing Intentions. In previous years, the purchasing patterns of consumers have become a cause for concern, considering the number of interactions with consumers who have specific behavioral goals for various issues. Intentional purchases have many definitions according to the nature of a study, which may vary. A few analysts have said that consumers' evaluations of and positive reasons for choosing an item or brand can be equated with purchasing intentions: "therefore, purchasing intentions are defined as the buying decision of an object or administration for a company based on the study of the specific components of the decision to acquire it" [33]. The focus for numerous consumers has remained purchasing intentions towards fast food (as expectations for buying fast food).

The analysis shows that people who are knowledgeable about quality are less likely to buy private brands [14]. In addition [34], consumers with an overwhelming urge to buy private labels were surveyed again. Purchasing intentions are of extraordinary importance to researchers and should be extensively studied. The motives for purchasing an item (as targets for fast food) play a significant role in the decision to purchase it. Consumers' intentions affect the decision to purchase an object [35]. It was noted in one study that expectations play a key role in people's actions.

To a consumer, the purchasing goal is the most significant aspect of purchasing decisions. The business sector claims that purchasing intentions reflect plans to buy a product in the future. The emphasis is placed on purchasing intentions in the marketing research that has been conducted in the field of consumer behaviors surrounding health goods, sports, and fashion, but the context of fast foods is still unexplored. Intentions are considered the basis for behaviors. Unique goals should be dealt with in the same way. Intending to work positively in accordance with such intentions is viewed as an intentional act. Intentions are central to behavior, as explained in planned action theory [36].

2.6. Influence of Awareness of Fast Food and UniquenessSeeking Traits on Fast Food Purchasing Intentions. Individuals never were equal; some are renowned and highly regarded for their intelligence, abilities, decisions, and actions, while others lack such abilities. Knowledge is the most desirable resource of the various skills and assets an individual can possess, and it is crucial for success.

Many consumers engage in simple educational process. When a new product is mysterious and consumers lack details, some never choose to try it. Learning about a product can trigger customers to choose something new. Therefore, information is a necessity for all people. The value and advantages of knowledge in our everyday lives become evident by studying the past.

This is the most anticipated variable in various fields, as indicated by innovation, leading to the introduction of new products and the development of highly efficient technologies [37]. Technology can be viewed as a tool that is built for a variety of learning uses. As has been noted, "then innovation should be taught as a type of knowledge-like learning" [38].

Innovation depends, according to the scientists above, on learning about a specific subject. Essentially, in the field of design and fashion, consumers' preferences for various 
brands depend on their understanding of the brands [39]. This research explores the effect of fast food awareness on attitudes toward such food and the purchasing decisions related to it. The existing work also aims to analyze the foodbuying goals and attitudes of consumers and the role of awareness of fast food in directing the purchasing intentions of consumers. The quest for variety/uniqueness dictates that new products should be distinct from the standard offerings. If people have been exposed to the same things for a long time, something new is needed to get consumers' attention. Thus, the products offered by a business, i.e., food, clothes, or any other product used by humans, must be varied. Therefore, we propose the following hypotheses:

\section{$\mathrm{H}_{1}$ : knowledge of fast food affects fast food purchasing intentions. \\ $\mathrm{H}_{2}$ : uniqueness-seeking traits affect fast food pur- chasing intentions.}

2.7. Influence of Attitudes toward Fast Food on Fast Food Purchasing Intentions. An attitude may reflect support for or disagreement with a person, place, object, or purpose; it is primarily psychological and necessary [33]. The transformation of psychology unfolds unpredictably, as the actions demonstrate a person's identification and the large-scale identity of others. In multiple studies, indeed, several meanings have been proposed by various researchers. Distinguished scholars and clinicians have alternately taken different approaches, as their results suggest.

In this respect, the behaviors studied by various fields, such as brain science, reasoning, guidance, etc., are generally regarded as variable. Attitude is a more widely studied variable that can influence fast food purchasing goals. Most marketing experts have chipped away the mindsets of consumers, metrics, and effects of various things on individual behaviors. As [14] demonstrates, an advertiser plays a key role in the creation of promotional systems. The behavioral consequences are often examined, but their bearing on fast food purchasing behaviors is still at the forefront of the discussion.

This study is meant to help marketers recognize how attitudes toward fast food affect the desire to purchase it and the degree to which it is necessary to cater to the food habits of consumers. The attitude of consumers toward fast food in developed nations has evolved, but it is still underemphasized in developing nations such as Pakistan. Ideally, this inquiry will address fast food-related concerns in developing countries such as Pakistan and help marketers on a large scale.

\subsection{Impact of Social Influences on Fast Food Purchasing} Intentions. One outstanding source of the most analyzed variables on community impact is whether the majority is believed to embrace a proposition. The existing literature has demonstrated substantial evidence indicating that the support of large numbers of people has a consistently greater impact on consumers' purchasing preferences than the quantitative alternatives [40].
In any case, minorities are increasingly persuading themselves similarly under certain conditions of straightline procedures (for instance, Baker and Petty (1994)), and when the results are inconclusive, private research is being performed on transitional disposition to identify consumers' intentions for branded goods [41]. Unlike the reliability of supply, some instruments seem to feed toward marginal subscribing for the dominant portion. If a large part of the system initiates a heuristic agreement and contributes to regular, strong acceptance, the least is a complicated system [17].

2.9. Impact of Awareness of Fast Food and Uniqueness-Seeking Traits on Attitudes toward Fast Food. Assessments that consider themselves, other persons, various items, and various concerns are defined as universal assessments. As the extensive definition suggests, attitude is one of many variables that are not necessarily observable [42].

Later, three variables were surveyed, which shape mindsets and can have an increased or decreased relationship with these components. Nevertheless, recent work indicates that only a few variables are necessary to establish an attitude [43]. Attitude is a persuasive factor that influences the social perceptions of consumers regarding various subjects. Thus, analysts have become concerned that this variable can be explored from multiple perspectives. Analysts have looked at a person's mentality, what forms a personality, and the changes that can influence holistically to analyze it.

Examinations from past years remind us of various factors that affect behavior but are considered less applicable to fast food. For example, the influence of information about fast food and the desire for uniqueness can be great, but researchers need data to analyze the effect on attitudes toward fast food. Individual characteristics are aspects of consumers' personalities, and they may shift from one person to another. The characteristics of personality are varied between people. These features are important for researchers to understand.

People tend to become bored with old things and hunt for new ones. People spend time and money buying various kinds of food, including non-perishable items, non-fast foods, cooked foods, and homemade foods. Some individuals may have strongly positive attitudes toward buying new products (overly enthusiastic) [44]. Therefore, we propose the following hypotheses:

$\mathrm{H}_{3}$ : knowledge of fast food affects attitudes toward fast food.

$\mathrm{H}_{4}$ : uniqueness-seeking traits affect attitudes toward fast food.

2.10. Impact of Knowledge of Fast Food and UniquenessSeeking Traits on Fast Food Purchasing Intentions in View of the Mediating Effect of Attitudes toward Fast Food. For several of the experiments, assertiveness according to various concepts and digital definitions was used as an intermediary. This variable reflects consumers' attitudes in 
practice (theory of planned conduct) according to various beliefs. Attitude as a mediator was measured, and it was found to have a significant impact on behavior. As a mediator, the attitude of an existing ecological model was applied [45]. Knowledge plays a role in the development of positive or negative attitudes toward a commodity [46]. We tested the proposition that information can become a justification for an attitude toward a product. Consumer demand depends on consumers' awareness of a commodity [47].

Consumers' actions and attitudes are affected by individual differences. Thanks to their various features, consumers continue to buy new goods and are encouraged to do so, which increases their satisfaction. Such characteristics have been studied by many researchers because of the significance of uniqueness-seeking features. It has been found that insolence in education fluctuating among people is due to the fact that the essence is different [48]. Students' level of learning activity was also measured by the learning motivation of students and based on students' patterns of acquiring new knowledge [49].

$\mathrm{H}_{5}$ : attitudes toward fast food mediate the relationship between knowledge of it and fast food purchasing intentions.

$\mathrm{H}_{6}$ : attitudes toward fast food mediate the relationship between uniqueness-seeking traits and fast food purchasing intentions.

\subsection{Moderating Effect of Family Structure on the Relationship} between Attitudes toward Fast Food and Fast Food Purchasing Intentions. To our understanding, family structure has no significant influence on consumers' fast food purchasing decisions, that is, the influence of family structure has not been explored in this way before. According to [50], family structure has little effect on attitudes.

On the other hand, however, a theory called the value credential norm theory explains that various family values and attitudes influence the conduct of an individual. They also have a significant impact on family structure [51]. It is easier to assume that the attitudes and actions of the family unit are controlled. Therefore, differences in family structure have a major effect on children's care and decision-making powers or abilities. After numerous family structure studies and experiments, it was concluded that the alteration of a single variable within a family can generate a lot of variance in the attitudes or actions of people.

$\mathrm{H}_{7}$ : family structure mediates the connection between consumers' attitudes and behaviors regarding fast food and fast food purchasing intentions.

\section{Research Model and Methodology}

3.1. Research Purpose. The goal of this study is to investigate the effect of awareness, attitudes, social influences, and family structure on purchasing intentions related to fast food (Figure 1). Attitudes toward fast food are well documented in the academic literature, but how does family structure (joint or nuclear) affect them? What about the effect on fast food purchases? The connection between the two variables has not been properly examined; however, a few inquiries about this structure have demonstrated their exceptional importance due to their effects on the behaviors of consumers. Family composition has implications for the health of adults because people with two parents typically have sound health in comparison with people raised by single parents (Dawson, 1991). The influence of family structure can be seen in the correlation between fast food attitudes and purchases. This is measured by a scale measuring family units.

3.2. Choice of Method. Regarding the research methodology, the quantitative approach and systematic data collection relate to the quantitative process defined by Brown [52]. In this type of research, many participants are necessary; therefore, comprehensive data collection is used to assess data trends. This study's key hypothesis is that family structure guides the connection between fast food-related attitudes and fast food purchasing intentions. This hypothesis was evaluated using a methodology in which participants had to answer items on a questionnaire in a predetermined order.

\subsection{Operationalization of Variables and Research Design}

3.3.1. Knowledge of Fast Food. Knowledge is viewed as the most significant variable impacting individuals' disposition and conduct. Individuals often make choices based on the degree of insight they possess. Cantin and Dubé (1999) noticed that attitudes related to sustenance hold some significant highlights of conviction as awareness of qualities and accommodation. They additionally discovered that attitude has some other significant components related to feelings and emotions. In the present examination, knowledge is considered awareness of fast foods. It implies that a person possesses knowledge of information related to fast food items, their brands, and other relevant data.

Measurement. For this examination, knowledge was measured using an eight-item scale, which was modified by Flynn and Goldsmith (1999). The participants' reactions were measured using a five-point Likert scale ( 1 for "unequivocally concur" and 5 for "emphatically oppose"). We used a one-dimensional scale.

3.3.2. Uniqueness-Seeking Traits. It has been shown in various articles that the desire to seek out uniqueness motivates consumers. How to manufacture products that capitalize on the disposition to seek novel food items merits consideration. Individuals become bored with the standard offerings, and they seek newer ones. Additionally, individuals like to experiment with various kinds of sustenance, such as convenience foods, broiled foods, and home-cooked meals. Adding a bit of variety here and there expands the appeal of food. 


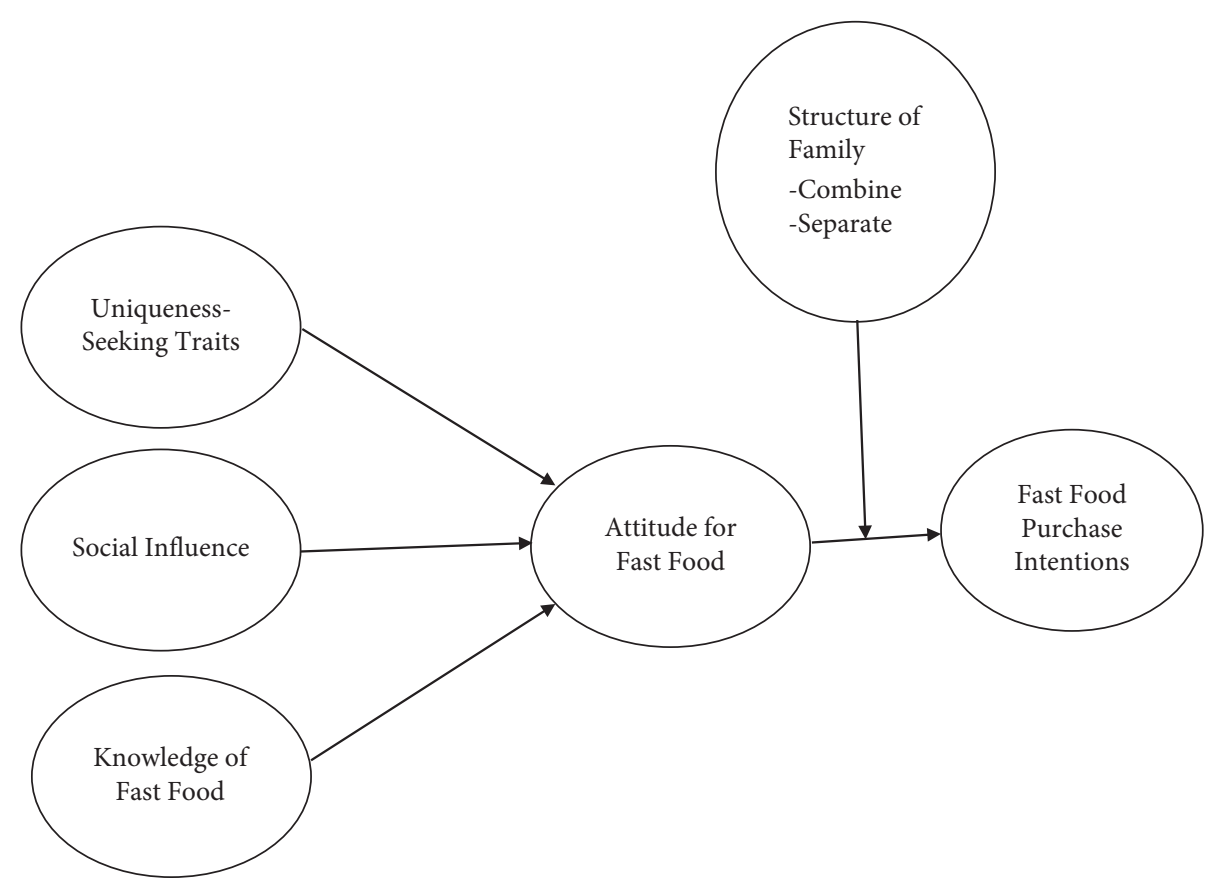

FIgURE 1: Conceptual framework.

Individuals often seek out various sorts of nourishment just to check them out or to enjoy their uniqueness and taste. They may also want to seek alternative types of nourishment just to enjoy something different and escape the everyday fare that bores them. The need for variety in sustenance has attracted some attention (Foxall, 1993). In this examination, uniqueness-seeking qualities are operationalized as identity attributes that influence individuals to purchase new items. The tendency to seek out new items if the existing ones do not meet their needs is an identity characteristic of numerous individuals.

Measurement. The measurement scale that was utilized here was created by Campbell and Goodstein (2001). This scale includes seven items. The participants' reactions were measured on a five-point Likert scale ( 1 being "emphatically concur" and 5 being "firmly oppose").

3.3.3. Attitude toward Fast Foods. Our concurring hypotheses of attitude are based on three significant components: knowledge, convictions, and contemplation. Attitude is a strong inclination that has the propensity to influence an individual's conduct. Attitude is characterized as "a longsuffering association of inspirational, enthusiastic, perceptual, and subjective procedures concerning some part of our condition" (Hawkins, Best and Coney, 2004). Attitude can compel individuals to carry on with a specific goal in mind. Solomon et al. (2002) found that attitude plays a role in the general population's decisions related to nourishment and various other items. In the present investigation, "attitude" is described as one's disposition toward fast food, which implies that a consumer's attitude has the power to affect their conduct concerning fast food purchasing decisions.
Measurement. A four-item scale was utilized to quantify attitudes. It was created based on the work of Yi and Jeon (2003). A five-point Likert scale was utilized to measure the participants' reactions ( 1 being "firmly concur" and 5 being "unequivocally oppose").

3.3.4. Fast Food Purchasing Intentions. Aims are viewed as forerunners of conduct. Consumers demonstrate their goals through their conduct. If a consumer has optimistic views of fast food, he/she will, without a doubt, demonstrate positive conduct toward it as well. Thus, consumers' goals have remained a focal point for advertising analysts. As Wong and Merrilees (1998) discovered, consumers' purchasing intentions with respect to design items were impacted by bigname support. Furthermore, Jobber (2000) found that consumers' purchasing goals regarding an item were affected by their purchasing power and their estimation of the impact of the item. Consumers' expectations have been examined with respect to many topics, yet fast food purchasing goals in developing nations like Pakistan have not been adequately examined.

A seven-item unidimensional scale created by Grewal et al. (1998) was used to calculate fast food purchasing intentions. Purchasing intentions were operationalized as purchasing intentions toward fast food items.

3.3.5. Family Structure. There are numerous types of family structures across the world. Each family structure has its own benefits, which can be contrasted with those of the others. With such distinctions in mind, specialists have done numerous investigations to discover the effects of such distinctions. Family structure has not been adequately examined as an arbitrator of the connections between two 
variables, yet a few inquiries have demonstrated its extraordinary significance in terms of people's conduct. As Dawson (1991) reported, family structure impacts an individual's choice of profession, as individuals who grow up with both parents generally have more solid identities and basic leadership skills than those who grow up with only one parent. Family structure was thus utilized as a mediator of the connection between attitudes toward fast food and fast food purchasing intentions. A scale accounting for combined families and family units was used to estimate these variables.

3.3.6. Social Influences. The scale used is composed of fivepoint Likert-type estimations of the significance of a predefined facet of one's character. We adopted three items from the four-item scale utilized by Kleine and Kernan (1993). Arnett, German, and Hunt (2003) referred to Callero (1985) as the inspiration for their system; however, they made some minor adjustments to the setting of the scale (being a graduate of a specific college).

\subsection{Data Collection}

3.4.1. Instrument. A self-directed survey was utilized to gather the data. Knowledge of fast food was estimated using an eightitem scale (for example, "I feel very educated about fast food"); it was adopted from Flynn and Goldsmith (1999). Similarly, the uniqueness-seeking attribute was estimated via seven items (for example, "when something becomes exhausting, I like to seek out new experiences") in view of the work of Campbell and Goodstein (2001). To gauge mentalities toward fast food, we drew on the work of Yi and Jeon (2003) with four items (for example, "I like fast food more than other types of food"). Lastly, consumers' intentions to purchase fast food were estimated using seven items (for example, "my probability of acquiring a fast food item is high") adapted from Grewal, Krishnan, Baker, and Borin (1998). Concerning family structure, we utilized a system with 1 indicating "joint family" and 2 indicating "family unit." The scale demonstrated the degree to which a consumer possessed unwavering qualities $(\alpha=0.892)$. The participants' responses to all the items were recorded on a five-point Likert scale ( 1 being "firmly agree" and 5 being "unequivocally disagree"). The surveys were disseminated and were offered to shoppers at fast food outlets and stores that sold fast food.

Unwavering qualities were demonstrated by Cronbach's alpha coefficient. The data collected are considered reliable if Cronbach's alpha coefficient is at least 0.7 (Cronbach, 1951). According to Peterson (1994), a Cronbach's alpha value of 0.6 is adequate. A value under 0.7 demonstrates that the data gathered are flawed and cannot be considered reliable. Values roughly equivalent to 0.7 are considered adequate. One variable in the present investigation (uniqueness-seeking qualities) had a Cronbach's alpha value of 0.679 , which was slightly under 0.7 .

3.4.2. Sample Selection. The participants of the investigation were shoppers at selected stores. Likewise, some of the responses were taken from shoppers at stores that were not dedicated to selling fast food. The group of participants included 279 consumers who patronized the chosen stores according to the standard created by Chou and Bentler (1986): $10^{*} 27=270$. For exactness, the test estimate was extended to 279. Another method was utilized for data collection; inspection of existing data is the most common data collection procedure when an adequate sample cannot be gathered. Nine additional cases were added to increase the rigor of the investigation.

3.5. Data Collection Procedure. The sample for the examination was composed of consumers visiting selected stores in the Multan region of Pakistan. Multan is divided into four towns: Musa Pak, Mumtazabad, Shershah, and Shah Rukne Alam. The marked stores carried items from five noteworthy fast food brands, including K\&N's, Menu, PK, Dawn, and Monsalwa, and five stores were chosen in each town. In addition, five non-marked stores, which carried items from the previously mentioned brands, were likewise chosen in each town. We finished the review in five weeks. During the study, a total of 875 consumers were asked to complete the survey. A total of 342 consumers consented to provide responses, of which 279 were utilized for the investigation. The remainder were disposed of because of inappropriate answers or missing data.

In this examination, we utilized a survey as the instrument for gathering the data. It was utilized to assess knowledge about fast food, uniqueness-seeking qualities, attitudes toward fast food, fast food purchasing aims, and family structure. With the assistance of the survey, knowledge of fast food, uniquenessseeking qualities, fast food purchasing expectations, attitudes toward fast food, and family structure were assessed. Various marked fast food outlets and other stores were visited during the data collection process. The respondents at the selected locations were asked to fill out the survey. The respondents were additionally reassured that the data gathered from their responses would be utilized only for the investigation and for instructional purposes and that their data would remain confidential.

It was not a simple undertaking to gather knowledge from the participants while they were shopping. Nonetheless, the shoppers were asked repeatedly to participate and they were monitored while filling out the survey. A few people declined to fill out the survey, while many of them acknowledged the request and complied. Time was the fundamental constraint, as many people did not have enough time to purchase their items and fill out the survey. In any case, after many visits to the stores that sold fast food, the data collection process ended. Some of the respondents requested remuneration for filling out the survey; however, they were not compensated because of concerns that the answers would be biased. The vendors played a significant role in the gathering of knowledge, as they asked shoppers to fill out the survey and collected some surveys later from shoppers who were in a rush and could not fill them out right away.

3.6. Data Analysis and Processing. The current version of SPSS (v. 20) was used for the data analysis. An ACD (auxiliary condition displaying) analysis with AMOS 
(analysis of moment structure) was used for this investigation. Statistical Package for the Social Sciences (SPSS) software was utilized to analyze the collected data and characterize the scale during the survey coding. In addition, the appropriate responses were further investigated according to the requirements of this investigation. When necessary, AMOS was also used to examine the data obtained using structural equation modeling (SEM).

To assess the reliability of the model we used in the examination, SPSS software was used. Furthermore, SPSS software was used to understand the data in relation to the terminology of the measurements. To verify the results achieved through the examination, investigative variable analysis (IVA) and confirmatory variable analysis (CVA) were used. Furthermore, to examine the proposed speculations in the investigation and model, SEM was used. Auxiliary equation modeling (AEM) was also used as a fundamental capability of AMOS to check the model by removing the esteem structure of the SPSS knowledge sheet.

3.6.1. AMOS and SEM. AMOS (v. 5) is an add-on module in SPSS that has two major components: AMOS graphics and AMOS BASIC. AMOS graphics provides an explanation of the work using graphs, diagrams, and graphical descriptions of the model. AMOS BASIC gives equational explanations of the model. These AMOS features are important because they can be used to produce a reliable period for measurement and for bootstrapping any issues or errors.

3.6.2. SEM. SEM can be used to deal with large numbers in statistical models and is useful in calculations of important theories with large amounts of data, as is explained by Lei and $\mathrm{Wu}$ (2007). General linear modeling (GLM) methods include multiple linear regression and analysis of variance (ANOVA). SEM is of more importance than GLM because it has the added quality of making it possible to find hidden variables and their connections with various methods. This application is useful and can be applied to cross-sectional data, longitudinal data, experimental data, and non-experimental data. Moreover, Lei and Wu (2007) explained that for hidden constructs, another application called confirmatory factor analysis is helpful. It is better to state that the SEM model explains the distribution of two models, that is, the measurement model and path model. Through the use of SEM analysis, a study can include diagrams of connections, predictions, and a summary of the model that has been described in it. The main objective of using SEM is to predict whether a hypothesis is constant with the data collected. A hypothesis is verified depending on which level is examined by the constancy of the model and its fitness summary.

\section{Data Analysis and Research Findings}

4.1. Factor Analysis of Knowledge of Fast Food. Eigen analyzed two variables in which there was only one element at variable 2; there was no extreme or solid association, but it was slightly more prominent than the variable 1 relationship. Therefore, just one calculation of eight items was retained for
KFF. The specific characteristics were initially calculated with only one measurement and seven components. After EFA, the characteristics were identified, and three CST items were removed due to the absence of relationships with the elements (items one, six, and seven). In addition, two possible CST variables were found, as shown in Table 1. Fast food-related behaviors had only one measurement in the beginning, and, after EFA, a single measurement remained because EFA had not demonstrated any other conceivable possibility. AFF was done in consideration of all the items, as shown in the table below.

First, fast food purchase intent (FFPI) was conceived of as a unit of measurement for seven items, but one additional measurement was tested using EFA. One aspect (item two) was examined with EFA and removed, as it had a lower weight. Table 2 shows outstanding results with stacking of greater than 0.5 . Four items were classified under social control, and, after a factor review, all four items remained. The threshold was met by all the items. Therefore, we did not remove any of the items.

4.2. KMO and Bartlett's Test of Sphericity. The examination of the findings for KMO and the test for the construction proposed by Bartlett are given in Table 3. Fast food information was an autonomous variable and required one test; it included eight items in this study. The items were inspected using the main application of CFA, model fitness assessment, but only seven items remained due to the disadvantageous stacking of items when EFA was continued based on fast food knowledge. CFA was only applied to KFF at first. The value of the unwavering combination quality was 0.714 , as shown in Table 4.

Initially, uniqueness-seeking traits were used as a free variable for the model with seven items, all of which applied to the whole model. The stacking of such items with a nonsubstantial load was rejected when the EFA analysis was conducted. The average reliability rating was 0.689 . Right off the bat, it was necessary to use CFA to create a layout that suits in a single way, as mentioned in Table 5.

The establishment of a value representing disposition toward fast food, which was necessary because of the subsequent investigation, consisted of four items, as an EFA analysis depends on a predetermined number of variables, and the initial application of CFA is linked to this process after the successful application of EFA. All of the variables has a relapse load over 0.5 , but, after the initial results, nothing was rejected. Issues appeared in the table following the initial CFA analysis. The composite dependability of the construct was 0.761 , as is mentioned in Table 6 .

Fast food purchasing expectation, which, in this study, is a dependent variable, consisted initially of seven items. It was a one-mass construct. Following the successful use of EFA, six items remained and one item was excluded due to poor measurement stacking depending on the set number of variables in the EFA examination. CFA is linked on this construct after EFA's first order. It changed concurrently due to weak institutionalized recurrence loads. Each variable had an adequate institutionalized rebound $(>0.4)$ weight, so 
TABLE 1: Factor analysis of KFF (knowledge about fast food).

\begin{tabular}{lccc}
\hline & Initial items (8 items) & Final items (7 items) \\
Dimensions & Items & Dimensions & Items \\
\hline KFF & KFF1, KFF2, KFF3, KFF4, KFF5, KFF6, KFF7, KFF8 & KFF & KFF1, KFF2, KFF3, KFF4, KFF6, KFF7, KFF8 \\
\hline
\end{tabular}

TABLE 2: Factor analysis of food social influence.

\begin{tabular}{lccc}
\hline Dimensions & Items & Dimensions & Items \\
\hline SI & SI1, SI2, SI3, SI4 & SI & SI1, SI2, SI3, SI4 \\
\hline
\end{tabular}

TABLe 3: KMO and Bartlett's test.

\begin{tabular}{lccccc}
\hline $\begin{array}{l}\text { KMO and } \\
\text { Bartlett's test }\end{array}$ & $\begin{array}{c}\text { Knowledge } \\
\text { about } \\
\text { frozen food }\end{array}$ & Change-seeking traits & $\begin{array}{c}\text { Attitude } \\
\text { toward frozen food }\end{array}$ & $\begin{array}{c}\text { Frozen } \\
\text { food purchase } \\
\text { intentions }\end{array}$ & $\begin{array}{c}\text { Social influence } \\
\text { Kaiser-Meyer-Olkin }\end{array}$ \\
measurement of sampling adequacy & 0.707 & 0.791 & 0.755 & 0.817 & 0.863 \\
Approx. chi-square & 486.165 & 351.373 & 304.753 & 660.875 & 308 \\
Bartlett's test of sphericity DF & 28 & 21 & 6 & 21 & 20 \\
Sig & 0.000 & 0.000 & 0.000 & 0.000 & 0.000 \\
\hline
\end{tabular}

TABLE 4: Model fit summary (confirmatory factor analysis of knowledge about fast food).

\begin{tabular}{|c|c|c|c|c|}
\hline \multirow[t]{2}{*}{ Quest. item } & \multirow{2}{*}{\multicolumn{2}{|c|}{$\begin{array}{l}\text { Item wordings } \\
\text { In-group bias }\end{array}$}} & \multicolumn{2}{|l|}{ Final } \\
\hline & & & Standardized loading & $\mathrm{CR}$ \\
\hline KFF1L & \multirow{2}{*}{\multicolumn{2}{|c|}{$\begin{array}{l}\text { Quite familiar about frozen food } \\
\text { I am one of the experts in frozen food among my circle of } \\
\text { friends }\end{array}$}} & 0.395 & 4810 \\
\hline KFF2L & & & 0.559 & 6403 \\
\hline KFF3L & \multicolumn{2}{|c|}{$\begin{array}{l}\text { I hardly ever come across a frozen food brand that I have } \\
\text { not taken notice of }\end{array}$} & 0.618 & 6.767 \\
\hline KFF4L & \multirow{2}{*}{\multicolumn{2}{|c|}{$\begin{array}{l}\text { I know pretty well about frozen food } \\
\text { I know less about frozen food as compared to most other } \\
\text { people }\end{array}$}} & 0.694 & 7.047 \\
\hline KFF6L & & & 0.375 & 4.800 \\
\hline KFF7L & \multirow{2}{*}{\multicolumn{2}{|c|}{$\begin{array}{l}\text { I really do not know a lot when it comes to frozen food } \\
\text { About new frozen food brands that are around I have heard } \\
\text { of most of them }\end{array}$}} & 0.267 & 3.487 \\
\hline KFF8L & & & 0.569 & \\
\hline \multirow{2}{*}{ Model fit } & $\mathrm{CMIN} / \mathrm{DF}\left(\chi^{2} / \mathrm{DF}\right)$ & GFI & TLI & CFI \\
\hline & 2.755 & 0.975 & 0.913 & 0.960 \\
\hline
\end{tabular}

TABLE 5: Model fit summary (confirmatory factor analysis of uniqueness-seeking traits).

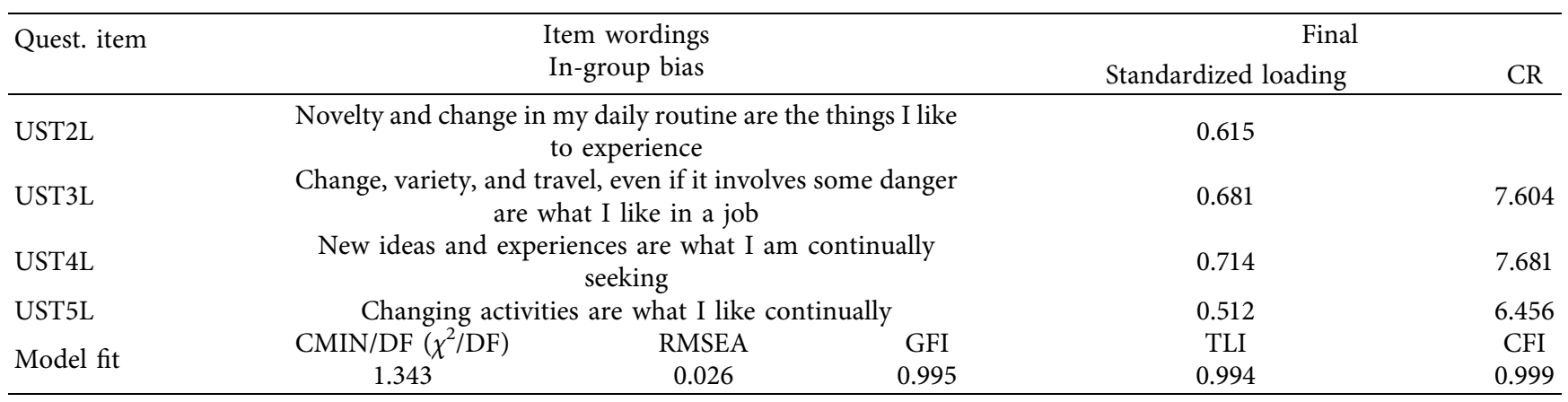


TABLE 6: Model fit summary (confirmatory factor analysis of attitude toward fast food).

\begin{tabular}{|c|c|c|c|c|}
\hline \multirow[t]{2}{*}{ Quest. item } & \multirow{2}{*}{\multicolumn{2}{|c|}{$\begin{array}{l}\text { Item wordings } \\
\text { In-group bias }\end{array}$}} & \multicolumn{2}{|l|}{ Final } \\
\hline & & & Standardized loading & $\mathrm{CR}$ \\
\hline AFF1L & \multicolumn{2}{|c|}{ I like frozen food more than others } & & \\
\hline AFF2L & \multicolumn{2}{|c|}{ For frozen food I have a strong preference } & 0.692 & 7.543 \\
\hline AFF3L & \multicolumn{2}{|c|}{$\begin{array}{l}\text { When I have a need for a product as a food I give prior } \\
\text { consideration to frozen food }\end{array}$} & 0.782 & 6.607 \\
\hline AFF4L & \multicolumn{2}{|c|}{ To others I would recommend frozen food } & .719 & 6.602 \\
\hline \multirow{2}{*}{ Model fit } & $\mathrm{CMIN} / \mathrm{DF}\left(\chi^{2} / \mathrm{DF}\right)$ & GFI & TLI & CFI \\
\hline & 1.771 & 0.997 & 0.985 & 0.997 \\
\hline
\end{tabular}

after the first CFA application, nothing was excluded. The issues are shown in the table following the first CFA submission. The fusion of efficiency was 0.824 , as shown in Table 7.

4.3. Overall Model Fitness. Through means of ailing CFA's and EFA's previously deliberated measurements for the entire scope, the model is discussed in the following section. So far, the calculation model for the dependent and independent variables has been the topic of discussion. Through this method, eight items were removed to achieve the best model according to the results achieved by conducting EFA and CFA on the first order. Due to small, consistent packaging and the irritated filling of an item with many aspects, some items were excluded from the model.

All aspects of the model have been studied to verify its fitness, and a covariance check of the dependent and independent covariances according to arbitrary variables was developed. When five additional items were excluded, the overall model became more efficient. Therefore, the final 13 elements (Table 8 ) of the various constructions match the data and measurement model. Thus, eight items were removed to provide a suitable statistical model.

4.4. Construct Validity. Method approval is a notable review method that provides a fundamental basis for validating the discovery process and whether a theory is pragmatic. If a review of an instrument must occur, the material concerns and issue of legitimacy will be examined, as shown in Table 9.

There is no general difference (the method in this paper has already been debated) in this paper. The criteria are valuable for confirming or rejecting the hypotheses' validity. Fast food purchasing expectancy (FFPE) has a significant impact on single feed purchasing (SFP) at $(p<0.05$, beta $=0.357)$. Fast food knowledge has an intangible FFPI connection $(p>0.05$, beta $=-0.037)$. In all cases, CST's fast food disposal (FFD) has an interceding FFPI connection with $(p \leq 0.000$, beta $=0.112)$. Similarly, KFF has a large influence on the FFPI of AFF $(p \leq 0.000$, beta $=0.298)$. However, AFF has substantial influence on FFPI $(p \leq 0.000$, beta $=1.008)$, as shown in Table 10 .

4.5. Analysis of Hypotheses. The errors signify meaningless relationships between information about fast food and fast food purchasing intentions, with a $p$ value of 0.523 . $\mathrm{H} 1$, therefore, was not upheld, as it does not indicate a desire to buy fast foods. According to the results, possessing information about fast food has an impact on fast food purchasing intentions of -0.038 . The relationship, however, is not significant. It has been discovered that, in some way, the situation restricts past knowledge so that learning about fast food and pursuing the goal of survival have a positive relationship among other variables. This result further strengthens the negative link between knowledge of fast food and the intention to purchase it. Therefore, without the presence of two variables, there can be no relationship between or effect on each other.

The institutionalized evaluation of the CST-FFPI relationship reflects an estimate of .358 with a $p$ value of 0.002 (Table 11), showing that there is a critical connection between the two. A similar correlation was found in [53], which showed that people function organically according to personality characteristics that encourage them to buy the same foods or seek new ones. The findings therefore confirmed H2, which expresses the desire for individuality and seeks to identify characteristics that have a positive effect.

H3 reflects a $p$ value of 0.002 for the KFF-AFF relationship, which shows that knowledge of fast food has a large impact on fast food-related attitudes. Thus, the findings of the analysis endorse the existing ones. The positive links between knowledge and the popularity of a product (computers, foods, mobile telephones, and so on) have been identified. The fact that knowledge of consumer goods raises the probability of it being desired has been observed. The perception of specific goods thus generates a positive attitude weight of 0.296 using a normal regression.

The uniqueness-seeking attribute and fast food-related attitudes have a great relationship, reflecting a $p$ value of 0.038 . H4 is also maintained in this way. The past examinations are supported; the connection between these two variables is similarly supported by the current analysis. The present examination's findings legitimize the effect of uniqueness-seeking qualities on attitudes toward fast food. The weight of the normal recurrence is 0.358 .

Fast food-related attitudes appear to interfere with the connection between fast food knowledge and fast food purchasing intentions, with a $p$ value of 0.001 . Fast foodrelated attitudes fundamentally interfere with the link with uniqueness-seeking, which reflects attributes and fast food purchasing goals, with institutionalized repetitive loads and a $p$ value of 0.038 .

The results show a remarkable link between the willingness to purchase fast food and fast food purchasing 
TABLE 7: Model fit summary (confirmatory factor analysis of fast food purchase intentions).

\begin{tabular}{|c|c|c|c|}
\hline \multirow[t]{2}{*}{ Quest. item } & \multirow{2}{*}{$\begin{array}{l}\text { Item wordings } \\
\text { In-group bias }\end{array}$} & \multicolumn{2}{|l|}{ Final } \\
\hline & & Standardized loading & $\mathrm{CR}$ \\
\hline FFPI1L & Purchasing frozen food product has high likelihood & 0.563 & \\
\hline FFPI3L & $\begin{array}{l}\text { I would consider buying the frozen food product at the } \\
\text { price shown }\end{array}$ & 0.444 & 6.199 \\
\hline FFPI4L & $\begin{array}{l}\text { I would consider buying frozen food product with high } \\
\text { probability }\end{array}$ & 0.683 & 8.493 \\
\hline FFPI5L & My willingness to buy frozen food product is always high & 0.880 & 9.570 \\
\hline FFPI6L & $\begin{array}{c}\text { The probability of buying frozen food is high if I were going } \\
\text { to buy something to eat }\end{array}$ & 0.815 & 9.354 \\
\hline FFPI7L & Purchasing frozen food is the thing I would love to do & 0.514 & 8.000 \\
\hline & CMIN/DF $\left(\chi^{2} / \mathrm{DF}\right) \quad$ RMSEA $\quad$ GFI & TLI & CFI \\
\hline Model hit & 0.979 & 0.965 & 0.985 \\
\hline
\end{tabular}

TABle 8: Model fit summary.

\begin{tabular}{lccccc}
\hline & CMIN/DF $\left(\chi^{2} / \mathrm{DF}\right)$ & RMSEA & GFI & TLI & CFI \\
\hline Model fit & 2.420 & 0.061 & 0.989 & 0.945 & 0.924 \\
\hline
\end{tabular}

TABLE 9: Validities of the construct.

\begin{tabular}{|c|c|c|c|c|c|}
\hline \multicolumn{2}{|l|}{ Knowledge about fast food } & $\begin{array}{l}\text { Uniqueness-seeking } \\
\text { traits }\end{array}$ & $\begin{array}{l}\text { Attitude toward fast } \\
\text { food }\end{array}$ & $\begin{array}{c}\text { Frozen food purchase } \\
\text { intentions }\end{array}$ & $\begin{array}{c}\text { Social } \\
\text { influence }\end{array}$ \\
\hline Knowledge about fast food & 1 & & & & \\
\hline \multirow{5}{*}{ Uniqueness-seeking traits } & CR $(0.708,0.669)$ & & & & \\
\hline & $\begin{array}{c}\mathrm{r} \\
0.637^{* *}\end{array}$ & & & & \\
\hline & $\operatorname{AVE}(0.447$ & & & & \\
\hline & $0.402)$ & 1 & & & \\
\hline & $\begin{array}{c}\sqrt{ } \operatorname{AVE}(0.668 \\
0.634)\end{array}$ & & & & \\
\hline \multirow{6}{*}{ Attitude toward fast food } & CR $(0.775,0.669)$ & CR $(0.775,0.708)$ & & & \\
\hline & r $0.485^{* *}$ & & & & \\
\hline & AVE $(0.535$ & r $0.389^{* *}$ & & & \\
\hline & $0.402)$ & $\operatorname{AVE}(0.535,0.447)$ & 1 & & \\
\hline & $\begin{array}{c}\sqrt{ } \operatorname{AVE}(0.731 \\
0.634)\end{array}$ & $\sqrt{ } \operatorname{AVE}(0.731,0.668)$ & & & \\
\hline & CR $(0.839,0.669)$ & CR $(0.839,0.708)$ & CR $(0.839,0.779)$ & & \\
\hline \multirow{5}{*}{$\begin{array}{l}\text { Frozen food purchase } \\
\text { intentions }\end{array}$} & r $0.446^{* *}$ & r $0.495^{* *}$ & r $0.719^{* *}$ & \multirow{4}{*}{1} & \\
\hline & $\begin{array}{l}\operatorname{AVE}(0.569, \\
0.402)\end{array}$ & AVE $(0.569,0.447)$ & AVE (0.569, & & \\
\hline & $\sqrt{A V E}(0.754$ & $\sqrt{ } \operatorname{AVE}(0.754,0.668)$ & $\sqrt{ } \operatorname{AVE}(0.754$ & & \\
\hline & $0.634)$ & & & & \\
\hline & r $0.446^{* *}$ & r $0.495^{* *}$ & r $0.719^{* *}$ & r $0.495^{* *}$ & \\
\hline Social influence & $\begin{array}{c}\text { AVE }(0.569 \\
0.402) \\
\sqrt{ } \operatorname{AVE}(0.754 \\
0.634)\end{array}$ & $\begin{array}{l}\operatorname{AVE}(0.569,0.447) \\
\sqrt{ } \operatorname{AVE}(0.754,0.668)\end{array}$ & $\begin{array}{c}\text { AVE }(0.569 \\
0.535) \\
\sqrt{ } \operatorname{AVE}(0.754 \\
0.731)\end{array}$ & $\begin{array}{l}\operatorname{AVE}(0.569,0.447) \\
\sqrt{ } \operatorname{AVE}(0.754,0.668)\end{array}$ & 1 \\
\hline
\end{tabular}

Table 10: Direct and indirect paths on dependent variable.

\begin{tabular}{|c|c|c|c|c|}
\hline \multicolumn{5}{|c|}{ Direct effects-two-tailed significance (BC) } \\
\hline & Uniqueness-seeking traits & Knowledge about fast food & Attitude toward fast food & Social influence \\
\hline Attitude toward fast food & 0.039 & 0.002 & - & 0.001 \\
\hline Fast food purchase intentions & 0.002 & 0.521 & 0.002 & 0.021 \\
\hline \multicolumn{5}{|c|}{ Indirect effects-two-tailed significance (BC) } \\
\hline & Uniqueness-seeking traits & Knowledge about fast food & Attitude toward fast food & Social influence \\
\hline Attitude toward fast food & - & - & - & - \\
\hline Fast food purchase intentions & 0.002 & 0.522 & - & 0.001 \\
\hline
\end{tabular}


TABLE 11: Analysis of the moderator for latent constructs.

\begin{tabular}{lccccc}
\hline & $\begin{array}{c}\text { Chi- } \\
\text { square }\end{array}$ & DF & $\begin{array}{c}p \\
\text { value }\end{array}$ & Invariant? & \\
$\begin{array}{l}\text { Unconstrained } \\
294.052\end{array}$ & 122 & & & $\begin{array}{c}\text { Step 1. Provided chi-square and DF unconstrained and constrained models. The } \\
\text { thresholds (green cells) will be updated automatically. And provided the number of } \\
\text { gully } \\
\begin{array}{l}\text { constrained } \\
\text { Number of } \\
\text { groups }\end{array}\end{array}$ \\
325.421 & 134 & & & \\
$\begin{array}{l}\text { Difference } \\
\text { Chi-square thresholds }\end{array}$ & & 2 & & & \\
\hline
\end{tabular}

intentions, with a value of 0.00002 . Subsequently, support for $\mathrm{H} 7$ was strengthened. Based on the outcomes, attitudes toward fast food decidedly impact fast food purchasing intentions, with a weight of 1.009 .

\section{Conclusion and Limitations of the Study}

5.1. Conclusion. In recent years, the fast food industry has been developing rapidly, leaving the door open for various stakeholders. Along these lines, it has become important for advertisers to distinguish between the components driving consumers' aims when buying fast food. According to the Central Bureau of Statistics (CBS) (2006), fast food consumption is increasing among individuals. The rate of increase of fast food advertisements in Pakistan is $6.6 \%$ (DAWN Newspaper, 2012). As a result, consumers' expectations toward fast food have become a matter of concern for various parties, particularly food delivery services and advertisers because of the huge increase in the fast food market. Hence, no brand wants to pass up the chance to gain benefits from the expanding consumption of fast food. Therefore, it was essential to examine some potential factors in the development of this business sector. Subsequently, purchasing intentions regarding fast food were considered in an in-depth investigation of the reasons for the sector's development. The current examination is an examination that covers the impacts of two significant variables, uniqueness-seeking characteristics and knowledge of fast food.

Purchasing intentions toward an item (for example, fast food) have become a focal point for advertisers. A few scientists have stated that purchasing intentions reflect consumers' assessments of and positive reasoning toward an item or brand. Hsu et al. (1987) characterized purchasing intentions as shoppers' judgments of an item, which were dependent on assessments of various components. Individuals' purchasing expectations (as aims to buy fast food) remained the focal point of numerous researchers. Along these lines, in the current examination, we investigated the impacts of two significant variables on purchasing expectations toward fast food. A significant mediator called attitude toward fast food was included in the theoretical model, which mediated the connection between knowledge of fast food (KFF), uniqueness-seeking attributes (USA), and fast food purchasing intentions (FFPI). Family structure was considered a mediator of the relationship between attitudes toward fast food and fast food purchasing intentions. Family values impact the identities of their members and their basic leadership propensities and social aims. While one family framework may create hopeful, friendly, inventive, and uniqueness-seeking people, another may produce worriers, misers, and depressed people. Similarly, Lopata (1973) found that family frameworks do not simply create the identities of their members; they also impact their social expectations. Uniqueness-seeking qualities are identity characteristics and greatly influence consumers' attitudes and social aims. Thus, Gray (1987) concluded that a uniqueness-seeking demeanor is composed of a lot of characteristics that are reflected not only in responses to novel items or hazardous circumstances but also by the propensity to seek to purchase unusual objects. More precisely, uniqueness-seeking attributes guide an individual to purchase an item that is not quite the same as the rest. Similarly, knowledge of fast food encourages consumers to purchase it. As Erdem (1998) found, learning about new foods positively affects consumers' conduct and encourages them to purchase novel food items.

5.2. Research Implications. Current investigation has a noteworthy commitment from scholarly as well as authoritative points of view on account of the accompanying ramifications.

5.2.1. Academic Implications. The varied behaviors of consumers have created a lot of issues for marketers developing new strategies to promote their brands. Old strategies result in losses for fast food-producing companies, and using outdated manufacturing procedures to produce fast food results in failure. Consumers' purchasing expectations are their assessments/judgments of a product. Purchasing goals toward an item are dependent on shoppers' judgment of an item, which is dependent on an assessment of various elements (Hsu et al., 1987). Along these lines, a large portion of companies have undertaken activities to learn about and comprehend the various variables behind consumers' purchasing expectations with respect to various items. The reason for evaluating the variables behind consumers' fast food purchasing expectations is to improve fast food advertisements. Fast food marketers are expanding their work in Pakistan, but they are doing so incrementally. Therefore, it is necessary to discover the most influential factors behind consumers' fast food purchasing choices. This study contributes to the field in this regard by proposing some influential new variables and exploring their impact on the current fast food market. Through them, we can 
comprehend consumers' needs and meet them in most ideal manner. Fast food consumers are value-conscious. Some people also purchase fast food because they like its taste (BBC, 2013). Some other people purchase fast food for its health advantages (BFFF, 2013). Essentially, Young (2013) surveyed various groups' reasoning behind purchasing fast food, and he discovered that value was a significant variable. Nonetheless, besides these factors, knowledge of fast food and consumers' uniqueness-seeking qualities contribute a lot to the decision to buy fast food, as this investigation plainly shows. Knowledge has an impact on consumers' food purchasing intentions (Erdem, 1998). Furthermore, uniqueness-seeking qualities trigger individuals to purchase fast food, as they can satisfy their desire for change/uniqueness and fulfill their need to try new brands (Kivela, 2006). In this regard, the current study is a significant contribution to the knowledge of consumers' fast food purchasing intentions, and it is a valid study because the data were collected directly from shoppers at stores in large cities in Pakistan, including Multan. It became apparent through the writing of this paper that our previous ideas about knowledge of fast food and uniqueness-seeking attributes and their connection to fast food purchasing expectations were challenged. Consequently, in this investigation, we endeavored to fill this research gap.

5.2.2. Managerial Implications. This study provides useful insights for marketers to apply in practical decision-making processes, and the current study can point marketers in the right direction. As an SEM analysis either supports or invalidates a theory, similar results to those of previous studies were found in the current study. In this study, a clear direction was provided to help marketers understand fast food consumers' needs and design strategies according to them. Some of the most useful insights for marketing managers are discussed below.

In the study, we examined how fast food advertising should be targeted to consumers because this industry is not growing adequately in Pakistan, which is resulting in losses for stakeholders. Accordingly, by concentrating on consumers' knowledge of fast food and their uniqueness-seeking characteristics, marketers can create better systems to catch the attention of this expanding market and reap benefits. The pragmatic ramifications of basic leadership procedures also ought to be connected considering the fact that consumers' knowledge of an item plays a significant role in the decision to purchase an item. Essentially, consumers with uniqueness-seeking characteristics seek to purchase something novel or distinct from the ordinary. Moreover, managers, particularly promotion directors, must unmistakably comprehend that fast food is becoming another important form of sustenance for the general population of Multan and Pakistan overall. Thus, they must concentrate on consumers' knowledge of this novel kind of nourishment and the identity characteristics, such as uniqueness-seeking traits, that are common among fast food consumers. These two elements affect consumers' purchasing intentions, and thus they should become the focus of discussion of fast food marketing.
5.3. Limitations of the Study. As the examination was narrow, with only a couple of variables, it is possible that there are other endogenous variables that could have an impact on the dependent variable of fast food purchasing intentions. The existence of other possible variables or actors was ignored in the study, which could significantly affect the dependent variable of fast food purchasing intentions. In this study, the data indicating knowledge of fast food were gathered at selected locations from customers of fast food stores and from various outlets selling fast food in southern Punjab in Pakistan, specifically in a large city named Multan. Our understanding of the current research could be enhanced by collecting data from various locations within the country as well as from other countries. In this way, a detailed body of knowledge about the consumers of fast food could be obtained, as consumers from various countries could have different opinions. Another limitation of the study is the limited amount of data or the small size of the sample, which consisted of fewer than a few hundred respondents. By increasing the number of respondents, a deeper understanding could be achieved, and the reliability of the study could be increased. The study could also be enriched by including a mix of qualitative and quantitative research methods. Consumers from various types of households and those shopping at other types of stores could also be included to increase the study's validity. As Butler (1991) noted, the results related to similar concepts could be different in various circumstances.

In addition, new variables could be included in the model, including accommodation, cost, bundling, taste, and consumer well-being. Therefore, a longitudinal study could also provide a different result than this cross-sectional study because people tend to change their preferences with the passage of time. Due to time-related limitations, the data were collected from a specific age group, but other age groups were ignored. Therefore, additional age groups could yield different results. Children's responses could be collected, as they tend to like fast food more than their elders. Similarly, older people could be included to provide more varied responses. Hence, by changing the variables, data collection locations, and other demographic features, the study could be enriched.

5.4. Future Research Directions. This study was conducted according to a specific plan, and it provides direction and suggests other areas for research using advanced research tools. The suggestions provided for the future are as follows.

After replacing the constructs and increasing the complexity, a conceptual model could be developed. A study conducted for comparison with this one could be conducted by changing the sample set; it could be done on a crossnational or cross-country basis. In future studies, a probability sampling technique could also be used for the data collection process. We only analyzed the consumers of fast food in southern Punjab, but similar studies could be conducted in other regions of the country to identify whether the behaviors of consumers across the country are the same. Other variables that can affect the views of 
consumers toward fast food could be added in future studies, such as suitability, cost, packaging, taste, healthfulness, and so on. To achieve a better understanding of the influences on the goals of consumers of fast food, a longitudinal analysis could be done, as people's preferences tend to change over time.

\section{Data Availability}

The data used to support the findings of this study are included within the article.

\section{Conflicts of Interest}

The authors declare that they have no conflicts of interest.

\section{Acknowledgments}

This study was funded by the new style think thank of Shaanxi universities: Research centre for auxiliary chemistry and new material development, and Shaanxi University of Science and Technology and grant number (ACNM202202).

\section{References}

[1] B. J. Gogoi, "Changing consumer preferences: factors influencing choice of fast food outlet," Academy of Marketing Studies Journal, vol. 24, no. 1, pp. 1-17, 2020.

[2] F. Katt and O. Meixner, "Is it all about the price? An analysis of the purchase intention for organic food in a discount setting by means of structural equation modeling," Foods, vol. 9, no. 4, p. 458, 2020.

[3] H.-P. Chang, C.-C. Ma, and H.-S. Chen, "The impacts of young consumers' health values on functional beverages purchase intentions," International Journal of Environmental Research and Public Health, vol. 17, no. 10, p. 3479, 2020.

[4] J. Wang, T. L. Pham, and V. T. Dang, "Environmental consciousness and organic food purchase intention: a moderated mediation model of perceived food quality and price sensitivity," International Journal of Environmental Research and Public Health, vol. 17, no. 3, p. 850, 2020.

[5] W.-Y. Baek, H.-S. Song, D.-H. Kim, and K. K. Byon, "Causerelated marketing and purchase intention toward team-licensed products: moderating effects of sport consumers' altruism," Sustainability, vol. 12, no. 8, p. 3183, 2020.

[6] Y.-C. Shen and H.-S. Chen, "Exploring consumers' purchase intention of an innovation of the agri-food industry: a case of artificial meat," Foods, vol. 9, no. 6, p. 745, 2020.

[7] A. G. Palos Lucio, D. N.-H. Sansores Martínez, C. Olvera Miranda, L. Quezada Méndez, and L. Tolentino-Mayo, "Nutritional quality of fast food kids meals and their contribution to the diets of school-aged children," Nutrients, vol. 12, no. 3, p. 612, 2020.

[8] P. Thaichon, S. Quach, and J. Surachartkumtonkun, "Intention to purchase at a fast food store: excitement, performance and threshold attributes," Asian Journal of Business Research, vol. 9, no. 1, p. 81, 2019.

[9] F. Alshammari and Y. K. Kim, "Seeking and escaping in a Saudi Arabian festival," International Journal of Event and Festival Management, vol. 10, no. 1, 2019.
[10] T. Effertz, T. Teichert, and M. Tsoy, "Fast food, ads, and taste in a Russian child's mind," Psychology \& Marketing, vol. 36, no. 3, pp. 175-187, 2019.

[11] D. H. Park, "Virtuality changes consumer preference: the effect of transaction virtuality as psychological distance on consumer purchase behavior," Sustainability, vol. 11, no. 23, p. $6618,2019$.

[12] S.-G. Jung and J.-H. Jang, "The study of consumer attitude by psychical distance of cause related marketing target and Korean and Chinese consumers: focused on the brand awareness," Journal of Digital Contents Society, vol. 20, no. 7, pp. 1299-1305, 2019.

[13] Y. Zhong and H. C. Moon, "What drives customer satisfaction, loyalty, and happiness in fast-food restaurants in China? Perceived price, service quality, food quality, physical environment quality, and the moderating role of gender," Foods, vol. 9, no. 4, p. 460, 2020.

[14] H. H. Pérez-Villarreal, M. P. Martínez-Ruiz, and A. Izquierdo-Yusta, "Testing model of purchase intention for fast food in Mexico: how do consumers react to food values, positive anticipated emotions, attitude toward the brand, and attitude toward eating hamburgers?" Foods, vol. 8, no. 9, p. $369,2019$.

[15] J. B. P. Faucher, A. M. Everett, and R. Lawson, "Reconstituting knowledge management," Journal of Knowledge Management, vol. 12, no. 3, 2008.

[16] A. Chivandi and E. T. Maziriri, “An evaluation of ISO 22000 food safety standards awareness and implementation in Zimbabwean branded fast food outlets: customer, employee, and management perspectives," African Journal of Hospitality Tourism and Leisure, vol. 6, no. 2, pp. 1-24, 2017.

[17] A. Xiao, S. Yang, and Q. Iqbal, "Factors affecting purchase intentions in generation $\mathrm{Y}$ : an empirical evidence from fast food industry in Malaysia," Administrative Sciences, vol. 9, no. 1, p. 4, 2019.

[18] E. Moghimi and M. E. Wiktorowicz, "Regulating the fast-food landscape: Canadian news media representation of the healthy menu choices act," International Journal of Environmental Research and Public Health, vol. 16, no. 24, p. 4939, 2019.

[19] A. Munguía-Serrano, L. Tolentino-Mayo, F. L. Théodore, and S. Vandevijvere, "Nutritional quality of hidden food and beverage advertising directed to children: extent and nature of product placement in Mexican television programs," International Journal of Environmental Research and Public Health, vol. 17, no. 9, p. 3086, 2020.

[20] M. Nadányiová, "The brand building through viral marketing on social networks and its perception by different consumers' generations," Marketing Identity, vol. 6, no. 1/1, pp. 441-450, 2018.

[21] L. Wadolowska, J. Hamulka, J. Kowalkowska et al., "Prudentactive and fast-food-sedentary dietary-lifestyle patterns: the association with adiposity, nutrition knowledge and sociodemographic factors in polish teenagers-the ABC of healthy eating project," Nutrients, vol. 10, no. 12, p. 1988, 2018.

[22] N. Nabi, A. O'Cass, and V. Siahtiri, "Status consumption in newly emerging countries: the influence of personality traits and the mediating role of motivation to consume conspicuously," Journal of Retailing and Consumer Services, vol. 46, pp. 173-178, 2019.

[23] L. Neave, E. Tzemou, and F. Fastoso, "Seeking attention versus seeking approval: how conspicuous consumption differs between grandiose and vulnerable narcissists," Psychology \& Marketing, vol. 37, no. 3, pp. 418-427, 2020. 
[24] A. V. Cardello, S. L. Chheang, D. I. Hedderley, L. F. Guo, D. C. Hunter, and S. R. Jaeger, "Toward a new scale to measure consumers' "need for uniqueness" in foods and beverages: the 31-item FBNFU scale," Food Quality and Preference, vol. 72, pp. 159-171, 2019.

[25] N. I. Nwankwo, M. O. Ezenwa, C. A. F. Okoye, U. J. Aboh, and H. Oraetue, "Do personality traits and perceived stigma predict attitude towards help seeking behaviour among clients under psychiatric management," Practicum Psychologia, vol. 9, no. 1, 2019.

[26] R. Miglin, N. Bounoua, S. Goodling, A. Sheehan, J. M. Spielberg, and N. Sadeh, "Cortical thickness links impulsive personality traits and risky behavior," Brain Sciences, vol. 9, no. 12, p. 373, 2019.

[27] N. Souiden, W. Chaouali, and M. Baccouche, "Consumers' attitude and adoption of location-based coupons: the case of the retail fast food sector," Journal of Retailing and Consumer Services, vol. 47, pp. 116-132, 2019.

[28] T. Elobeid, I. Savvaidis, and V. Ganji, "Impact of food safety training on the knowledge, practice, and attitudes of food handlers working in fast-food restaurants," British Food Journal, vol. 21, no. 4, 2019.

[29] K. Stahlmann, A. Hebestreit, S. DeHenauw et al., "A crosssectional study of obesogenic behaviours and family rules according to family structure in European children," International Journal of Behavioral Nutrition and Physical Activity, vol. 17, no. 1, p. 32, 2020.

[30] E. Yarimoglu, I. Kazancoglu, and Z. A. Bulut, "Factors influencing Turkish parents' intentions towards anti-consumption of junk food," British Food Journal, vol. 121, no. 1, 2019.

[31] P. Butler and A. Hammer, "Pay progression in routinised service sector work: navigating the internal labour market in a fast food multinational company," Industrial Relations Journal, vol. 51, no. 4, pp. 351-371, 2020.

[32] R. Banik, S. Naher, S. Pervez, and M. M. Hossain, "Fast food consumption and obesity among urban college going adolescents in Bangladesh: a cross-sectional study," Obesity Medicine, vol. 17, Article ID 100161, 2020.

[33] M. Abrar, R. Shabbir, and I. Hussain, "Impact of customer animosity and attitude on purchase intention in fast-food industry of Pakistan," Pakistan Journal of Social Sciences (PJSS), vol. 39, no. 3, 2019.

[34] C. H. Liu and C. W. Liao, "The impact of key factors of the fast food restaurant on purchase intention," Global Journal of Business Research, vol. 13, no. 1, pp. 93-107, 2019.

[35] J. Liu and R. L. Bailey, "Investigating the effect of use and social cues in food advertisements on attention, feelings of social support, and purchase intention," Health Communication, vol. 35, no. 13, pp. 1-9, 2019.

[36] H. Jamal, "The perceived trustworthiness of electronic word of mouth (eWOM) on attitude towards dietary supplements, purchase intention and behaviour for dietary supplements amongst female adolescents in Saudi Arabia," Doctoral Dissertation, Middlesex University, London, UK, 2019.

[37] A. Rajput and R. Z. Gahfoor, "Satisfaction and revisit intentions at fast food restaurants," Future Business Journal, vol. 6, no. 1, pp. 1-12, 2020.

[38] J. H. Han, Y. H. Oh, and S. Ham, "Influence of ordering kiosk nutrition information transparency and information quality on the customer behavioral intention in fast food restaurants," Journal of the Korean Dietetic Association, vol. 25, no. 3, pp. 165-177, 2019.
[39] F. Quoquab, N. Z. M. Sadom, and J. Mohammad, "Driving customer loyalty in the Malaysian fast food industry," Journal of Islamic Marketing, vol. 11, no. 6, 2019.

[40] L. Zhao, S. H. Lee, and L. R. Copeland, "Social media and Chinese consumers' environmentally sustainable apparel purchase intentions," Asia Pacific Journal of Marketing and Logistics, vol. 31, no. 4, 2019.

[41] F. Rohman, Y. B. Abadi, M. Soelton, N. Prasetyo, and E. T. Saratian, "The effect of environmentally friendly paper toward purchasing intention," in Proceedings of the 2020 4th International Conference on Management, Economics and Business (ICMEB 2019), pp. 120-126, Atlantis Press, Zurich, Switzerland, February 2020.

[42] H. A. Majabadi, M. Solhi, A. Montazeri et al., "Factors influencing fast-food consumption among adolescents in Tehran: a qualitative study," Iranian Red Crescent Medical Journal, vol. 18, no. 3, 2016.

[43] R. M. Shamhuyenhanzva, E. Van Tonder, M. Roberts-Lombard, and D. Hemsworth, "Factors influencing Generation Y consumers' perceptions of eWOM credibility: a study of the fast-food industry," International Review of Retail Distribution \& Consumer Research, vol. 26, no. 4, pp. 435-455, 2016.

[44] Q. Nguyen, T. M. Nisar, D. Knox, and G. P. Prabhakar, "Understanding customer satisfaction in the UK quick service restaurant industry," British Food Journal, vol. 120, no. 6, 2018.

[45] A. Harun, G. Prybutok, and V. R. Prybutok, "Insights into the antecedents of fast-food purchase intention and the relative positioning of quality," Quality Management Journal, vol. 25, no. 2, pp. 83-100, 2018.

[46] J. R. Hanaysha and R. J. Pech, "Brand prestige and the mediating role of word of mouth in the fast food industry," Global Business Review, vol. 19, no. 6, pp. 1494-1514, 2018.

[47] S. Sapic, J. Filipovic, and J. Dlacic, "Consumption in fast-food restaurants in Croatia and Serbia," British Food Journal, vol. 121, no. 6, 2019.

[48] U. Akram, A. R. Ansari, G. Fu, and M. Junaid, "Feeling hungry? let's order through mobile! examining the fast food mobile commerce in China," Journal of Retailing and Consumer Services, vol. 56, Article ID 102142, 2020.

[49] J. Lee Burton, J. Gollins, L. E. McNeely, and D. M. Walls, "Revisiting the relationship between ad frequency and purchase intentions," Journal of Advertising Research, vol. 59, no. 1, pp. 27-39, 2019.

[50] M. Ogorevc, K. Primc, R. Slabe-Erker et al., "Social feedback loop in the organic food purchase decision-making process," Sustainability, vol. 12, no. 10, p. 4174, 2020.

[51] M. S. Ahmad, A. Jamil, K. F. Latif et al., "Using food choice motives to model Pakistani ethnic food purchase intention among tourists," British Food Journal, vol. 122, no. 6, 2019.

[52] C. Brown, "Firms' choice of method of pay," ILR Review, vol. 43, no. 3, p. 165, 1990.

[53] B. Rolls, "Sensory specific satiety and variety in the meal," in Dimensions of the Meal, the Science, Culture, Business, and Art of EditingAspen Publishers, New York, NY, USA, 2000. 